\title{
Developing an Environmental Education programme to address factors behind weak Community Participation in Wildlife Resource Management in Mumbwa and Lupande Game Management areas in Zambia
}

\author{
Inonge Milupi, D*, Kaiko Mubita, Pauline Namakau Monde, Steriah, M Simooya \\ The University of Zambia, School of Education, Department of Language and Social Sciences Education, \\ Environmental Education Section, Zambia
}

*Corresponding Author: Inonge Milupi D, The University of Zambia, School of Education, Department of Language and Social Sciences Education.

\begin{abstract}
This study presents an Environmental Education (EE) programme that would aid in addressing factors behind weak community participation in wildlife resource management in Mumbwa and Lupande Game Management Areas (GMAs) in Zambia. The programme is based on the demographic profile of people living in the two GMAs which include ethnicity, sex and education. A total of 349 respondents from Lupande (173) and Mumbwa (176) and 12 key informants who include chiefs (7) and ZAWA officials (5) were interviewed. Structured interviews were analysed using SPSS software while informal interviews with key informants were analysed thematically. The study found that lack of sensitisation activities led to the weak community participation in the two GMAs. As an intervention programme, the study found that EE programmes would enhance community participation in wildlife resource management in the two study areas.
\end{abstract}

Key words: Community participation; environmental education; game management area; wildlife management; Zambia.

\section{INTRODUCTION}

The advocacy for the increase in community participation in natural resource management started in 1980. At that time, several international agencies such as the Department for International Development (DFID), United States Agency for International Development (USAID) and United Nations (UN), promoted the advocacy for the improved participation of the local community in natural resource management (Ferna'ndez, 2010). This was because the effective involvement of resource users in the management of their resources was perceived to enhance the quality and durability of environmental decision making (Reed, 2008; Rowe and Frewer, 2000). The importance of public participation in natural resource management has also been recognised by several international agreements such as Earth Summit (Luyet, et al.2012). Scholars such as Mashinya, (2007) and Mubita (2011) also noted that public participation in natural resource management has led to a sense of ownership and responsibility. Several studies conducted on of public participation in environmental programmes such as forest management (Buttoud and unusova 2002; Luyetet al., 2012), ecosystem management (Luyet, et al 2012) and wildlife management (Milupi et al 2017a; 2017b) have shown that public participation is a vital component of management system for achieving sustainability in natural resource management.

In Zambia, community participation in wildlife resource management is enshrined in the Zambia wildlife act of 1998 and 2015. The mode of participation is through local institutions called Community Resources Boards (CRBs) that are established under geographical chiefdom boundaries.Wildlife is one of the major natural resources that Zambia possesses. The formation of CRBs gave the local people the latitude to actively participate in and benefit from wildlife resource management. A total of 74 CRBs have been established throughout Zambia (GRZ 2014). Despite these efforts by the Zambian Government, community participation in wildlife resource management is still weak and has led to the loss of biodiversity in some parts in the country (MTENR, 2007; GRZ, 2014; Milupi et al. 2019). The reasons behind weak community participation in wildlife resource 
Developing an Environmental Education programme to address factors behind weak Community Participation in Wildlife Resource Management in Mumbwa and Lupande Game Management areas in Zambia

management in the GMAs in addition to inadequate benefits to local people is the lack of Environmental Education emphasis in the primary objectives ( table 1) of the Zambia Wildlife Authority an institution mandated to manage wildlife resources in the country.

The Zambian National Policy on Environment states that EE and awareness needed to be promoted through formal and non-formal education, by all government institutions, Non-Governmental Organisations (NGOs) including the private sector (Government of the Republic of Zambia Environmental Policy, 2007, p23). Primary objectives of ZAWA however do not include community sensitisation through EE (table 1).

Table1. Zambia Wildlife Authority Primary Objectives (Zambia Wildlife Act of 1998)

\begin{tabular}{|c|c|}
\hline Primary objectives of ZAWA & $\begin{array}{l}\text { - Protection and conservation of wildlife in } \\
\text { Zambia and to improve the quality of the life among } \\
\text { communities in the wildlife parks. } \\
\text { - To maintain the sustainability of biodiversity } \\
\text { in the national parks and GMAs. } \\
\text { - To ensure an increase in wildlife resources } \\
\text { - To improve wildlife resource management to } \\
\text { a level which will secure sustainable flow of benefits } \\
\text { from the resources; and } \\
\text { - To considerably improve the wildlife } \\
\text { resource base investment in co-operation with the } \\
\text { private sector and local communities. }\end{array}$ \\
\hline
\end{tabular}

Source: Zambia Wildlife Act, 1998

In order to enhance the weak community participation experienced in Zambia, this study aims at establishing an Environmental Education programme in ZAWA and CRBs in particular so as to improve community participation and the unsustainable use of wildlife resources in Mumbwa and Lupande GMAs using case study data from the two GMAs.

\subsection{Study Areas}

The study areas were Mumbwa and Lupande GMAs from Central and the Eastern provinces of Zambia respectively. Their selection was based on good performances in the collection of revenue by GMAs (MTA, 2018).

Mumbwa GMA (Figure 1) is located in Mumbwa district. It covers an area of approximately 3,370 square kilometres. It was proclaimed a GMA in 1972. The GMA lies between longitude 25058 ' to $26030^{\prime}$ E and latitude $14055^{\prime}$ to $15018^{\prime} \mathrm{S}$ and shares a boundary with the Kafue National Park (KNP) in the north (Figure 1). It is defined as a prime hunting area where highly valued trophy species such as buffalo (Syncerus caffer)), lion (Panthera leo) and leopard (Panthera pardus) are abundant (ZAWA, 2004). In terms of revenue generation, the GMA is ranked fifth of 21 GMAs where trophy hunting occurs (Lewis and Alpert, 1997). This makes it an important revenue generator for both the local communities and Zambia Wildlife Authority (ZAWA) who each obtain 50 per cent of the revenue from hunting. The human population of the Mumbwa GMA was estimated to be 33500 in 2012 (UNDP, 2012). Mumbwa GMA community comprises subjects in the three chiefdoms of Chibuluma, Kabulwebulwe, and Mulendema who form the wildlife management authority for Mumbwa GMA. Major threats and pressures affecting Mumbwa GMA include poaching and human encroachment (MTENR, 2007; Watsonet al. 2014). Others are charcoal production, illegal fishing when there is a ban on fishing and increased agricultural activities.

Lupande GMA (Figure 1) is located in Eastern province of Zambia in the Luangwa valley. The GMA is 120 kilometres west of the provincial headquarters at the town of Chipata. Lupande GMA is in Mambwe. Geographically the GMA lies between $1251^{\prime}$ and $1325^{\prime} \mathrm{S}$ and $3147^{\prime}$ and $322^{\prime}$ ' $\mathrm{E}$. (Figure 1). The GMA has a total area of 4,840 square kilometres. It is bordered by South Luangwa National Park (9,050 square kilometres) on the west, Chipata - Petauke district boundary in the south and Chipata - Lundazi district boundary on the north and East. The total population of Lupande GMA is estimated to be 68,918 people (CSO, 2012). Lupande GMA has six chiefdoms namely Kakumbi, Mkhanya, Nsefu, Jumbe, Malama and Msoro. 
Developing an Environmental Education programme to address factors behind weak Community Participation in Wildlife Resource Management in Mumbwa and Lupande Game Management areas in Zambia

The annual rainfall of the area is about 800 millimetres (Ndhlovu, 1991). Lupande GMA experiences two seasons and these are the dry season in May to October and the wet season from November to April). Dominant vegetation in Lupande GMA includes woodlands such as Miombo (Brachystegia, Isoberlinia, and Julbernardia species), Mupane (Borassus aethiopus) and Munga (Acacia albida). The majority of the people of Lupande are subsistence farmers who grow crops such as maize (Zea mays), cotton (Gossypium hirsutum), millet (Eleusine species), sorghum (Vulgare species), beans (Phaseolus vulgaris), pumpkins (Curcubita maxima) and sweet potatoes (Ipomoea batatas)( Nyirenda, et al., 2013). Other crops grown in the area include cassava (Manhot species), groundnuts (Arachis hypogea) and rice (Oryza sativa)(Nyirendaet al.,2013).

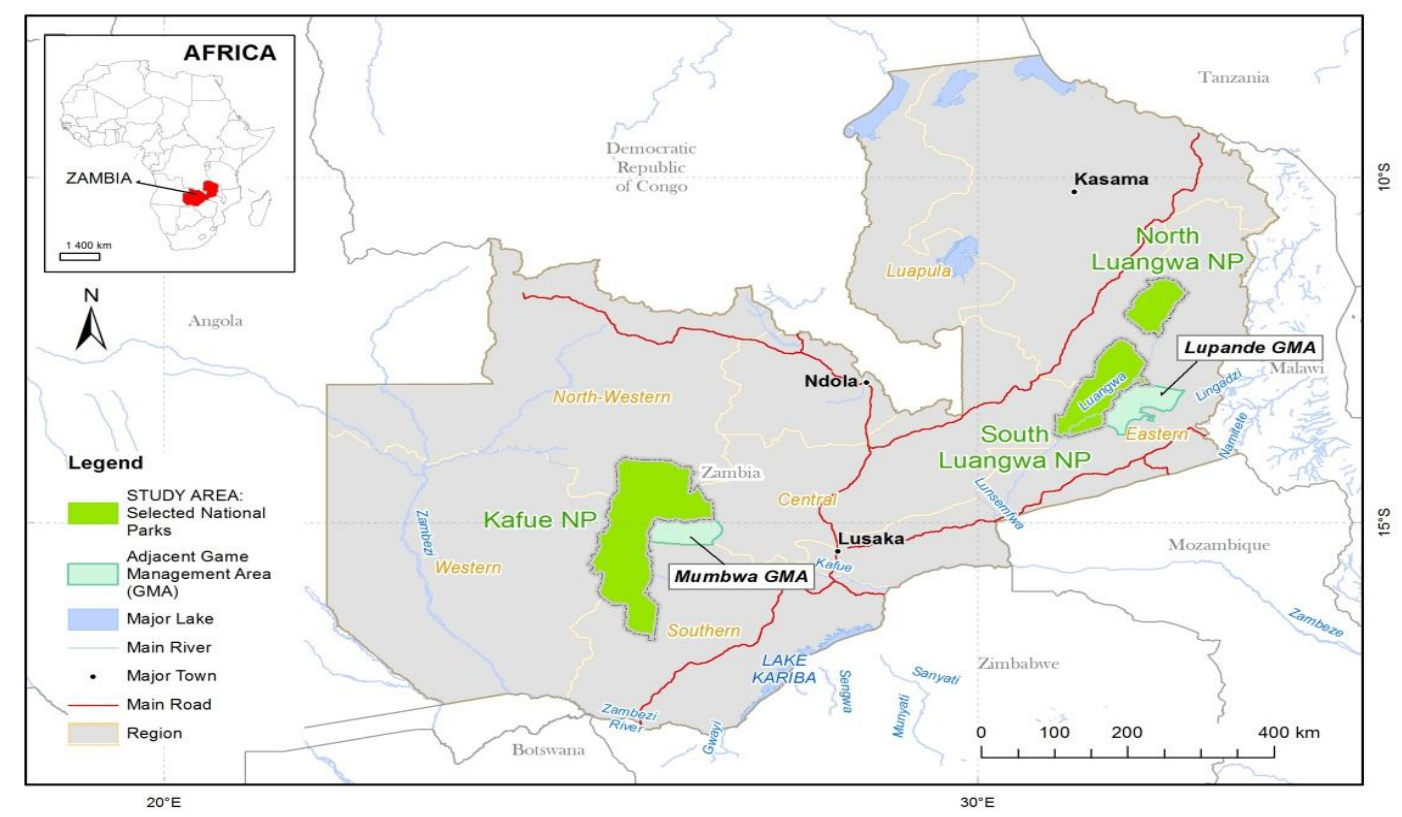

Figure2. Map of Zambia showing the location of National parks and Game Management Areas.

\section{MethodologY}

\subsection{Data Collection}

The three methods employed for data collection were a desk study of relevant legislation and regulations, structured interviews with 349 randomly selected villagers in the study area and semistructured interviews with 12 purposively selected key informants (seven chiefs and five ZAWA officials).

\subsection{Desk study}

Legislation and regulations pertaining to wildlife conservation in Zambia were reviewed to provide an overview of community participation in various CBNRM programmes and how EE enhanced community participation. Some of the legislation examined included Zambia Environmental Policy2007, Zambia wildlife Act of 1998 and 2015, national policy on environment 2007, published journal papers related to frameworks in social ecological systems and management of wildlife and ZAWA reports.

Furthermore the aspects likely to lead to effective community participation in wildlife resources were highlighted during this review. These included gender balance, lack of involvement in decision making process and lack of sensitisation activities. These documents provided current background information on the use of environmental education to protect natural resources.

\subsection{Structured Interviews}

Questionnaires were provided to 349 local people who were randomly selected from Mumbwa and Lupande GMAs. These comprised 176 from Mumbwa and 173 from Lupande. Three chiefdoms, 
Developing an Environmental Education programme to address factors behind weak Community Participation in Wildlife Resource Management in Mumbwa and Lupande Game Management areas in Zambia

Kabulwebulwe, Mulendema and Chibuluma, were covered by Mumbwa GMA. However, in Lupande GMA, only four chiefdoms of six were considered: Kakumbi, Mkhanya, Nsefu and Jumbe. The households were selected randomly from a list obtained from traditional authorities in each of the two GMAs. Every fifth household was selected and if no respondent was found in the fifth household the next one would be selected. The interviews were then conducted with the heads of the sampled households, who could be male or female. The households were interviewed on local community participation, empowerment, conflict resolution mechanism, gender balance, equity, conservation sensitisation and conservation of biodiversity.

\subsection{Semi-structured key informant interviews}

Information on experiences of community-based natural resources in the two study areas was collected by interviewing key informants from ZAWA and traditional leaders. The ZAWA officials were interviewed in English, while the traditional chiefs were interviewed in their respective local languages that included Kaonde, Lamba, Kunda and Chewa.

\section{RESUltS}

\subsection{Gender of Respondents}

Most respondents interviewed in the two GMAs were men (Figure 3). In Mumbwa GMA for example, female respondents interviewed were only $36.9 \% \mathrm{n}=65$ ) while men respondents were $63.1 \% \mathrm{n}=111$ ). In Lupande GMA, $(41.6 \% \mathrm{n}=72)$ respondents interviewed were females while men were $58.4 \% \mathrm{n}=$ 101) as shown in Figure 2

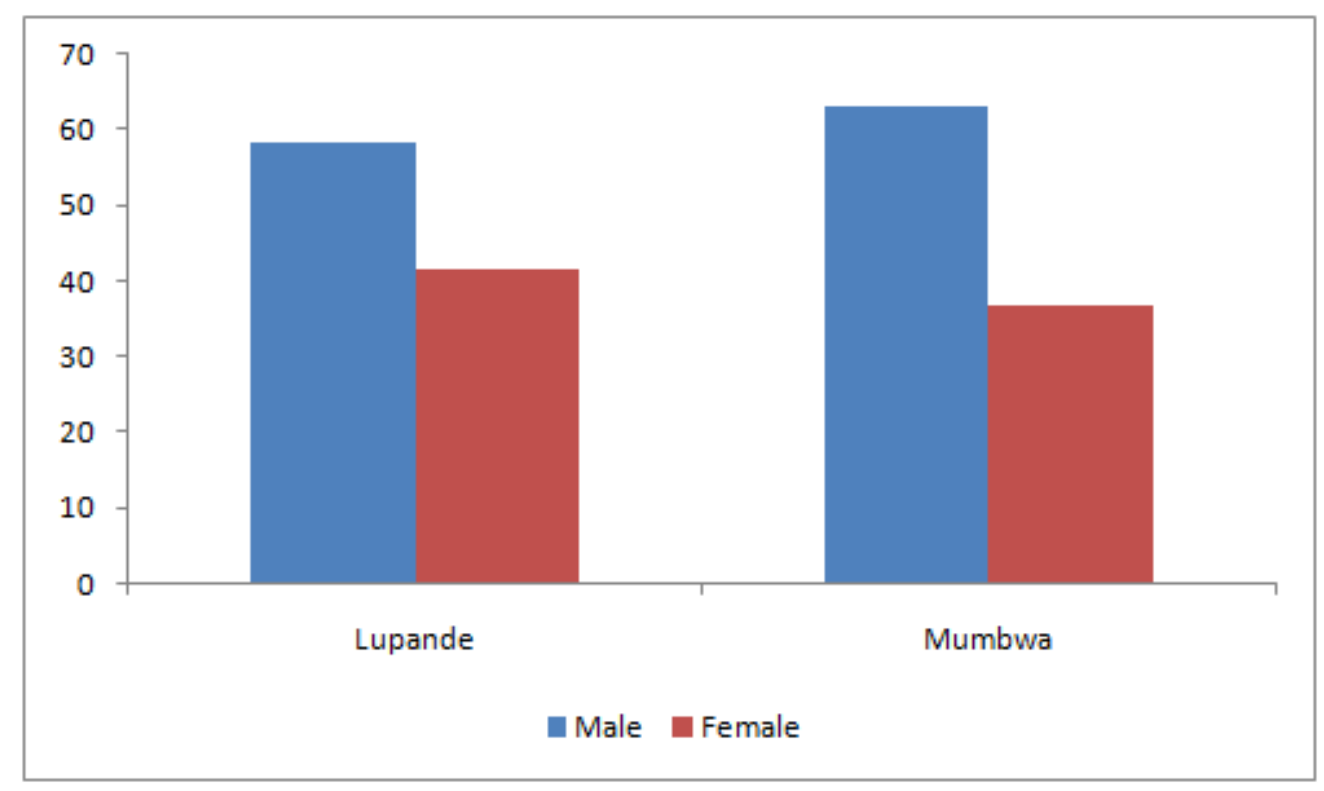

Figure2. Gender of respondents

Further, in Lupande and Mumbwa GMAs, women were less involved in wildlife management. This was because $80 \%$ of responses in Mumbwa GMA said fewer women were involved while in Lupapnde GMA, 69\% of respondents confirmed that fewer women were involved in wildlife management. Responses from key informants from the two GMAs also confirmed little participation of women in wildlife resource management. In the three chiefdoms found in Mumbwa GMA, for example, there were few women (10\%) employed as village scouts and in Lupande GMA only $17 \%$ of women were employed in the four CRBs that were visited.

\subsection{Age}

The highest number of respondents from Lupande GMA $(20.2 \% \mathrm{n}=35)$ were those who were aged 40 -44 years, followed by those aged $30-34$ years $(15.6 \% n=27)$. The fewest respondents were in the group aged $18-19$ years $(4 \% \mathrm{n}=7)$ (Figure 3$)$. 
Developing an Environmental Education programme to address factors behind weak Community Participation in Wildlife Resource Management in Mumbwa and Lupande Game Management areas in Zambia

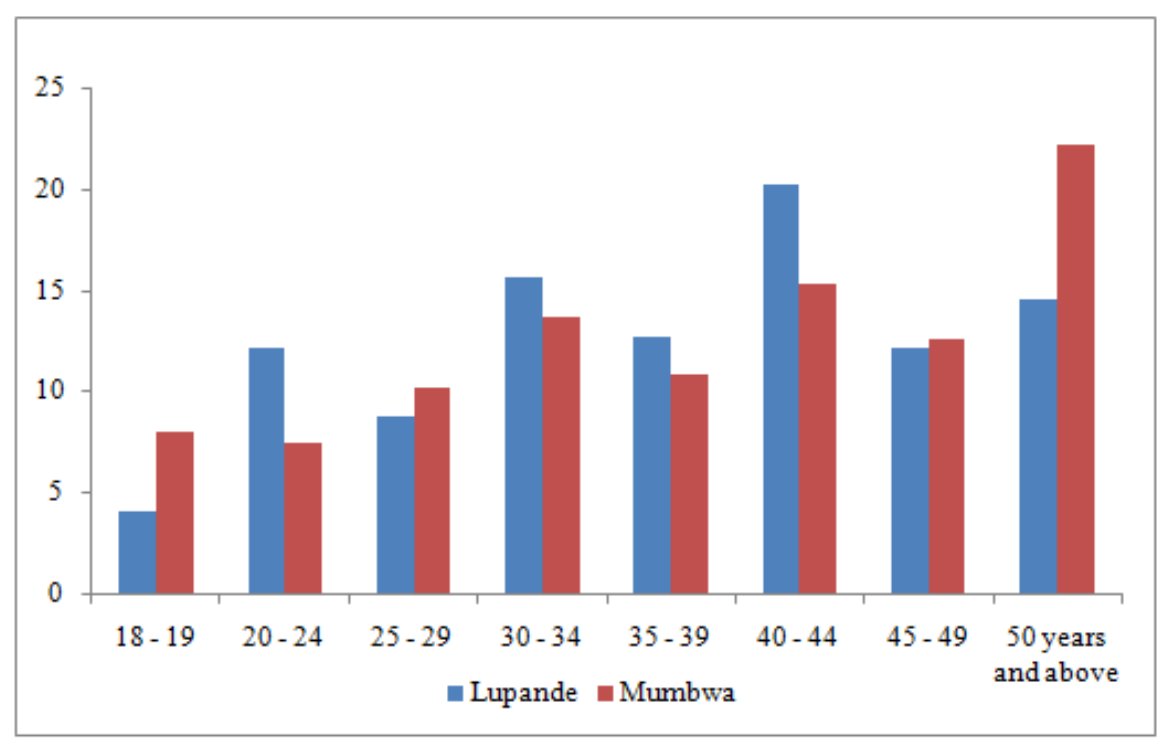

Figure3. Age distribution of respondents

\subsection{Education}

Twenty one point four percent ( $n=37)$ of respondents from Lupande and $(21.6 \% \mathrm{n}=38)$ from Mumbwa GMA had a secondary education while $(9.8 \% \mathrm{n}=17)$ and $(5.7 \% \mathrm{n}=10)$ from Lupande and Mumbwa GMAs respectively had no formal education (Figure 4).

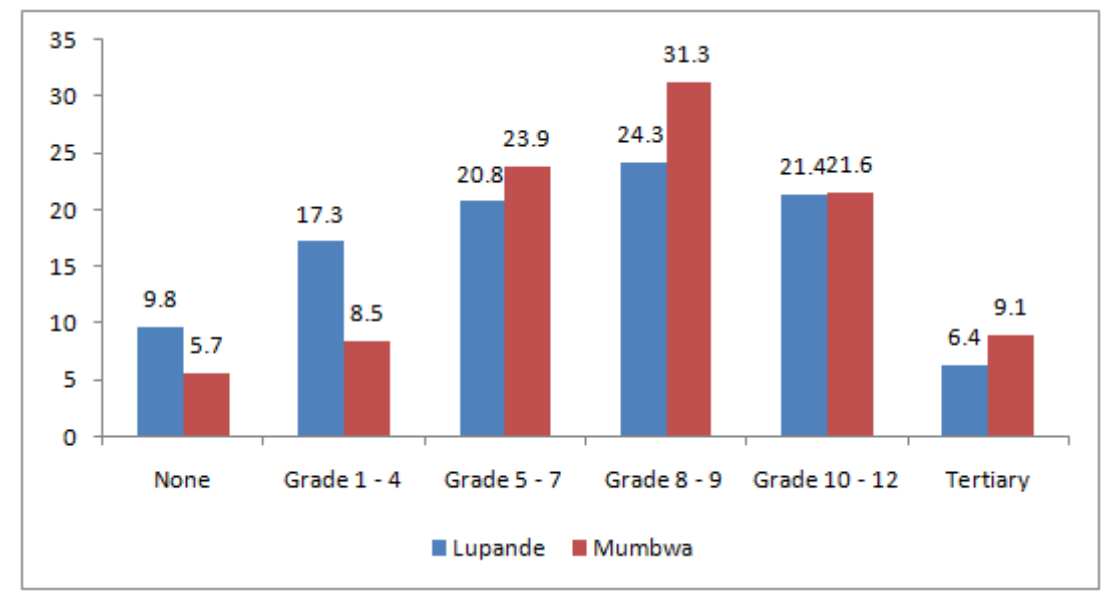

Figure4. Education level of respondents

\subsection{Ethnicity}

The majority of respondents in Lupande GMA were the Kunda speaking people $(72.8 \% \mathrm{n}=126)$ while, in Mumbwa GMA the Ila $(30.1 \% \mathrm{n}=53)$ and the Lozi $(21.0 \% \mathrm{n}=37)$ speaking people were the majority (Figure 5).

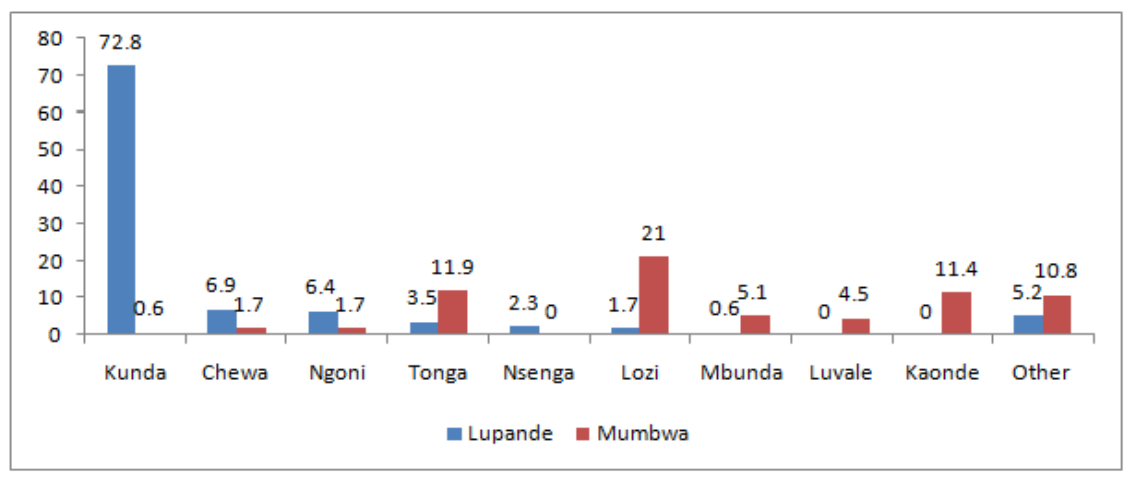

Figure5. Ethnicity of respondents 
Developing an Environmental Education programme to address factors behind weak Community Participation in Wildlife Resource Management in Mumbwa and Lupande Game Management areas in Zambia

\subsection{Community Involvement in Decision Making Process}

Most respondents (83\%) in Mumbwa were not involved in decision making processes regarding wildlife resource management while in Lupande GMAs 64\% believed they were not involved in decision making process. Only few respondents from Mumbwa (17\%) and Lupande (36\%) were involved in wildlife management programmes through being employed as village scouts in the Community Resource Boards (CRBs) in the GMAs. Their role was to help ZAWA in monitoring and enforcing the law by arresting poachers.

\subsection{Sensitisation Activities}

The study showed that there was lack of sensitisation activities in the two GMAs. In Mumbwa GMA, for example, there was a low level (13\%) observed in the GMA and in Lupande GMA only 39\% of sensitisation activities were noted in the area (Figure 6). Mostly these activities were conducted by non-governmental organizations such as Community Markets for Conservation (COMACO), Luangwa Conservation Management (LCM), South Luangwa Conservation Management (SLCM), and World Wide Fund for Nature (WWF). ZAWA was not very active in community sensitisation as their role was mostly seen to enforce the law and punish the offenders.

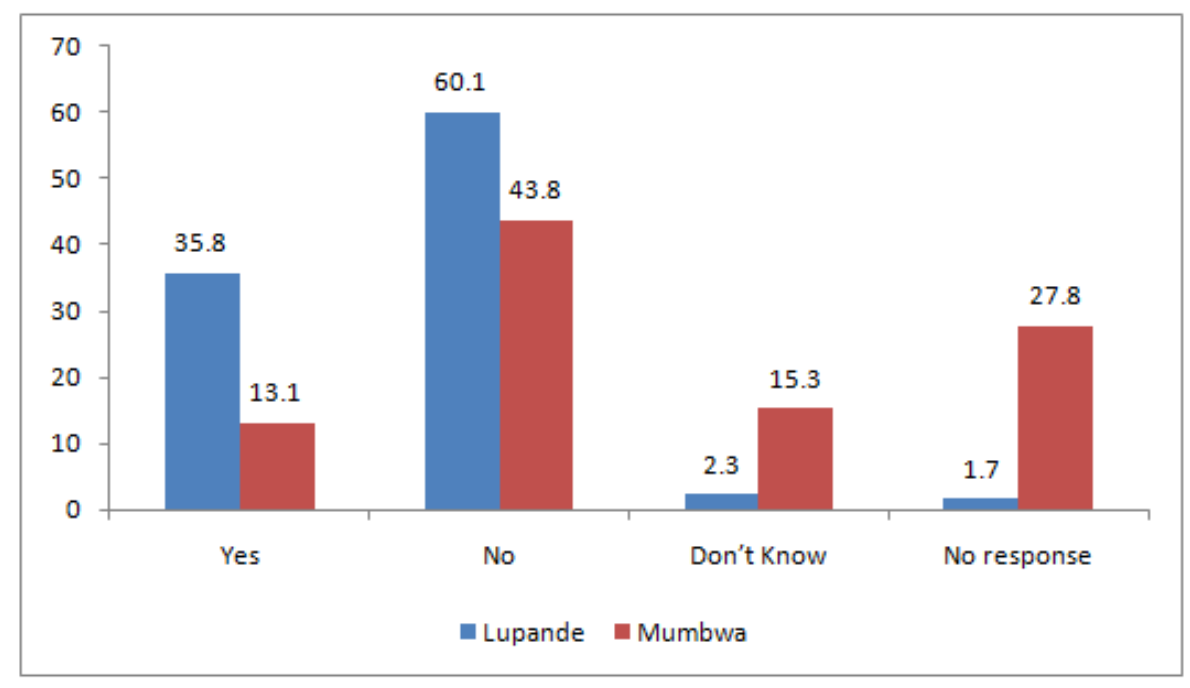

Figure6. Evidence of sensitisation activities

\section{DISCUSSION}

Gender: The study showed that there were more men than women in the two study areas. Despite the smaller number of women in both GMAs, both women and men were willing to be interviewed and therefore should be included in the EE programmes. This was because sex as observed by Liefländer, et al. (2012) and Milupi (2008) is influenced by environmental attitudes through environmental education.

Age group: The age group in both study areas indicated that youths were the majority of people who lived in the two GMAs. This signal was important for EE programmes as reviewed by Liefländer and Bogner, 2014 who observed that the younger the person is, the more connectedness he or she will have with nature and would therefore be more receptive to EE programmes.

Educational profile: The educational profile of respondents from the two GMAs clearly indicates that EE programmes could help in making the respondents understand the importance of sustainable use of wildlife resources. This is because the profile shows the diversity of educational levels from none to college level indicating different understanding levels of environmental issues. Conducting EE programmes in the two GMAs would therefore promote community participation and in the process improve the weak community participation currently prevailing in the two GMAs. This is because EE programmes target both the educated and those without education in increasing and enhancing public awareness and participation on environmental conservation. Mubita (2011) in his article titled 'Responding to disasters in tourism in the era of climate change in Zambia' also proposed that Education for Sustainable Development (ESD) should be in the context of tourism and natural 
Developing an Environmental Education programme to address factors behind weak Community Participation in Wildlife Resource Management in Mumbwa and Lupande Game Management areas in Zambia

resources conservation in order to increase and enhance public awareness and participation. It is also interesting to note that most respondents from Lupande and Mumbwa GMAs have secondary and tertiary education. This level of education entails that they could be able to read and understand conservation messages and be able to relay them to the elderly and those that do not have the necessary level of education. Furthermore, the use of posters and electronic media such as local radio stations or television could also be considered in EE programme as most respondents could read and write. Education and training for the environment was also proposed by Mubita et.al. (2020) as a major tool of advocating for change for environmental safety.

Ethnic groupings: The study further revealed a cross section of men and women from different ethnic grouping living in the two GMAs. Traditional norms of how to look after the environment differs from one ethnic group to another. Therefore, EE programmes should be carried out in different languages exhibited in the two study areas in order to cater for the many ethnic groups. This is important because people use elements of their culture to maintain their ecosystem (SPIMUN, 2014).The EE programmes in the two areas should therefore require background information in order to ensure appropriate design of the EE programmes which would enhance the local community's environmental attitudes (Lieflander and Bogner, 2014).

Community participation: The study showed that most respondents from both GMAs were not involved in making decision making regarding the management of wildlife resources. This indicates that there was inadequate community participation in wildlife resource management in the two GMAs. The introduction of EE programme in the two GMAs would therefore promote enhance community participation because as observed by Mubita et.al. (2020), Liefländer and Bogner 2014, education and public participation is one of the most effective tools for promoting public participation.

Sensitisation activities: The study showed lack of sensitisation activities taking place in the two GMAs. Lack of sensitisation activities is a recipe for illegal activities such as poaching. This is because the resource users lack important information that would promote understanding of the importance of sustainable utilisation of wildlife resources and further lead to behavioural change in the local resource users. Sensitisation through EE programme would encourage people to understand, appreciate and implement sustainable practices (Liefländer and Bogner, 2014; Mubita et.al. 2020). The EE programme in the area would therefore improve the weak community participation currently prevailing in the two areas. Community participation was also proposed by Mubita (2011) as a factor to improve tourism and wildlife management in the era of climate change in Zambia. This would not only promote active participation of the resource users in the management wildlife resources in the GMAs but would also enhance quality of environmental decision making Reed, (2008); Pumbert and Pretty (1994), Rowe and Frewer (2000) and also build sense of ownership in the resource users Mashinya, (2007).

Table2. Themes for the proposed Environmental Education Programme for addressing weak community participation in wildlife management

\begin{tabular}{|c|l|}
\hline \multirow{2}{*}{ Themes } & $\begin{array}{l}\checkmark \quad \text { Factors leading to weak community } \\
\text { participation }\end{array}$ \\
$\checkmark \quad$ Environmental education to address factors \\
behind weak community participation \\
$\checkmark \quad$ Environmental education to sensitise local \\
community on the disadvantages weak community \\
participation \\
$\checkmark \quad$ Environmental education to promote active \\
participation Environmental education to consider \\
demographic data during sensitisation programme \\
$\checkmark \quad$ Environmental education to consider the \\
dynamic nature of cultural beliefs \\
$\checkmark \quad$ Environmental education to utilize the \\
dynamic nature of demographic data
\end{tabular}

Source: Adapted from field data, 2014 
Developing an Environmental Education programme to address factors behind weak Community Participation in Wildlife Resource Management in Mumbwa and Lupande Game Management areas in Zambia

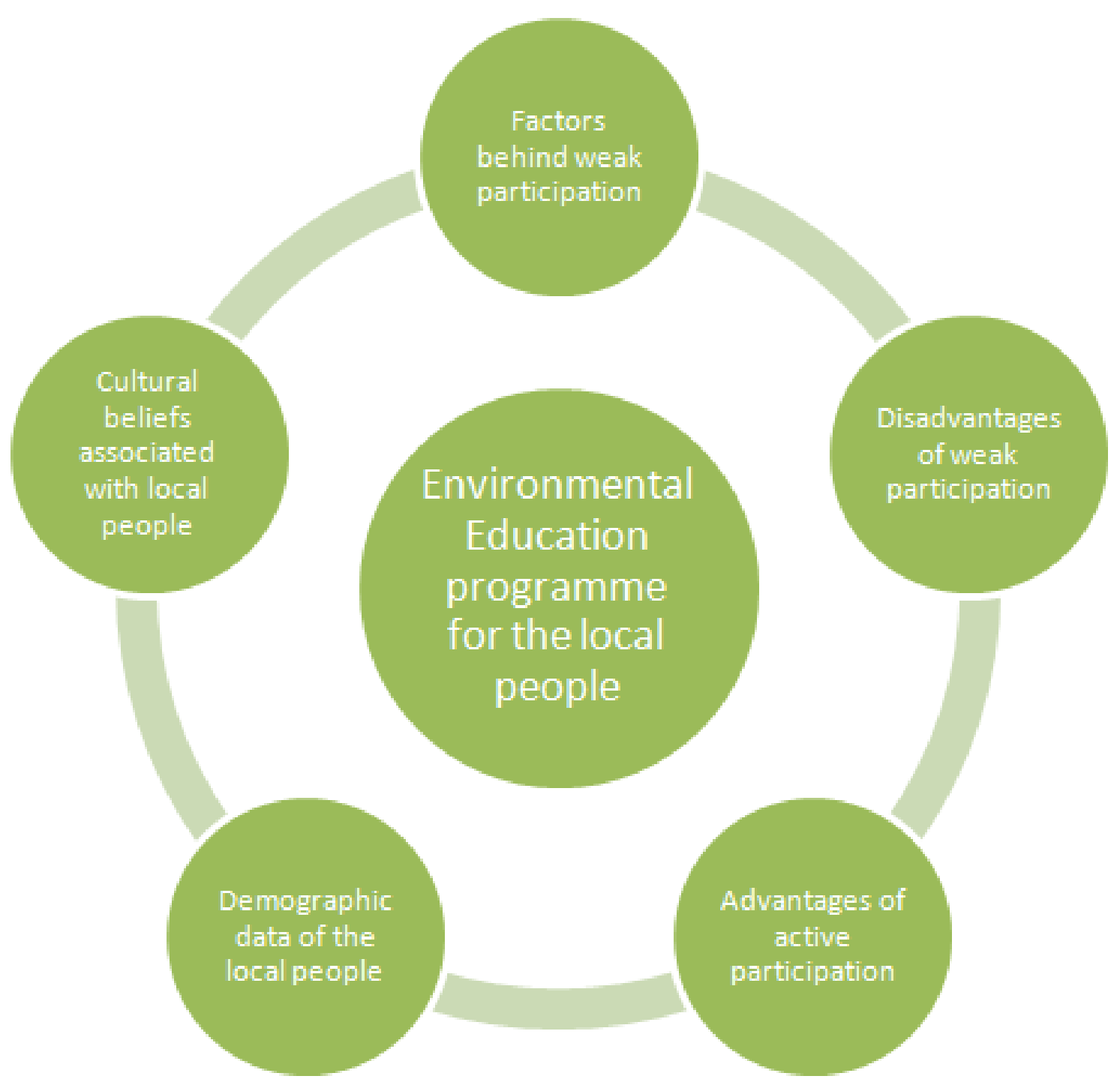

Figure8. Proposed Environmental Education Programme

Source: Adapted from field data, 2014.

\section{CONCLUSION}

The study revealed several demographic data which included gender, age, education, and ethnicity. The study further showed inadequate community participation and community sensitisation in the two areas. The proposed introduction of EE programmes in ZAWA and CRB institutions using dynamic nature of demographic and cultural norms exhibited in the two areas would enhance community participation and therefore mitigate the prevailing weak community participation in wildlife resource management in Mumbwa and Lupande GMAs.

\section{RECOMMENDATIONS}

- The study's findings reveal that Environmental Education is not one of the main objectives of ZAWA and CRBs. There is need for ZAWA to include EE among their main objectives.

- The study further indicated that sensitisation activities in the two areas were rarely conducted. ZAWA and CRBs therefore need to increase sensitisation activities in the two study areas in order to improve community participation in the two areas.

- The study also showed that the form of EE activities taking place in the GMAs did not consider demographic and cultural norms prevalent in the two areas. There is need for ZAWA to ensure that EE programmes taking place in the two areas should take into consideration the dynamic nature of demographic and cultural norms found in the two GMAs. 
Developing an Environmental Education programme to address factors behind weak Community Participation in Wildlife Resource Management in Mumbwa and Lupande Game Management areas in Zambia

- The research findings also pointed out that community participation is weak in the two areas. ZAWA should therefore introduction EE programmes in the areas in order to promote active participation of the local community in the management of their resources.

\section{ACKNOWLEDGEMENT}

We would like to thank ZAWA for permitting us to conduct research in Lupande and Mumbwa Lupande GMAs. We also thank all the entire respondents from Mumbwa and Lupande GMAs for their support and corporation for their precious time during our field study to be a success.

\section{REFERENCES}

[1] Arnstein S.R 1969. A ladder of citizen participation, Journal of the American Institute of Planners, 35: 216 $-224$.

[2] Buttoud, G. And Yunusova, I. 2002. A "mixed model" for the formulation of a multipurpose mountain forest policy; theory vs practice on the example of Kyrgyzstan. Forest Policy \& Economics, vol. 4 (2): 149160.

[3] Central Statistical Office (CSO), 2012. The national population and housing census for 2010. in Zambia. Central Statistics Office, Lusaka.

[4] Ferna'ndez, A. 2010 Wildlife conservation in Zambia: Impact of Game Management on households' welfare. Thesis presented to Michigan State University.

[5] Government of the Republic of Zambia Environmental Policy 2007. ECZ, Lusaka. 23.

[6] Kaiko Mubita, Inonge Milupi, Pauline Namakau Monde and Steriah, M Simooya. 2020. A Proposed Holistic Approach to Fire Safety Management in Zambian Markets. International Journal of Humanities Social Sciences and Education (IJHSSE), Vol 7, no. 11, 2020, pp. 93-101. doi: https://doi.org/10.20431 12349-0381.0711011

[7] Lewis, D. and Alpert, P. 1997. Trophy hunting and wildlife conservation in Zambia. Conservation Biology 11:59-68.

[8] Liefländer, A. K and Bogner F. X. 2014. The Effects of Children's Age and Sex on Acquiring ProEnvironmental Attitudes Through Environmental Education, The Journal of Environmental Education ttp://dx.doi.org/10.1080/00958964.2013.875511 Accessed 14/09/2019

[9] Lieflander, A. K., Fr “ ohlich, G., Bogner, F. X., \& Schultz, P. W. 2012. Promoting connectedness with nature through " environmental education. Environmental Education Research, 19, 370-384. doi:10.1080/13504622.2012.697545 Accessed on 13 th September, 2019

[10] Luyet, V, Schlaepfer R, Parlange M. B and Buttler, A. 2012. A framework to implement stakeholder participation in environmental projects. Journal of Environmental Management 111: 213-219

[11] Mashinya, J. 2007. Participation and devolution in Zimbabwe's CAMPFIRE programme: Findings from Dissertation submitted to the Faculty of the Graduate School of the University of Maryland, College Park.

[12] Milupi, I.D, Somers MJ, Ferguson W. 2017. Local ecological knowledge and community based management of wildlife resources: A study of the Mumbwa and Lupande Game Management areas (GMAs) of Zambia. South African journal of Environmental Education (SAJEE) 33: 25- 38.

[13] Milupi, I.D, Somers MJ, Ferguson W. 2017. A review of Community- Based Natural Resource Management (CBNRM). Journal of Applied Ecology and Environmental Research (AEER) 15(4): 1121 1143.

[14] Milupi, I.D, Somers MJ, Ferguson W. 2019. Inadequate community engagement hamstrings sustainable wildlife resource management in Zambia. Afr J Ecol.00:1-11. https ://doi.org/10.1111/aje.12685

[15] Milupi, I.D. 2008. Environmental education activities among Chongwe rural women of Zambia arising from environmental degradation of their area. Findings from a dissertation submitted to graduate school of the University of Zambia, Lusaka, Zambia.

[16] Ministry of Health (MOH). 2010. Mumbwa District Hospital, Republic of Zambia

[17] Ministry of Tourism, Environment and Natural Resources (MTENR), 2008. Reclassification and effective management of the national protected areas system project: Review and synthesis of lessons learned concerning optimum forms of community management structures for multiple resource management in Zambia and southern and eastern Africa.

[18] Ministry of Tourism, Environment and Natural Resources (MTNRM), 2007. Synthesis of completed management effectiveness tracking tool for protected areas managed by the Zambia Wildlife Authority, Lusaka, Zambia 
Developing an Environmental Education programme to address factors behind weak Community Participation in Wildlife Resource Management in Mumbwa and Lupande Game Management areas in Zambia

[19] Mubita, K .2011. Responding to disasters in tourism in the era of climate change in Zambia. A paper presented at the $5^{\text {th }}$ IIPT Conference, $15^{\text {th }}$ to $20^{\text {th }}$ May, 2011, Intercontinental Hotel, Lusaka, Zambia

[20] Nyirenda, V.R., Myburgh, W.J., Reilly, B.K. and Chabwela, H.N. 2013. "Wildlife crop damage valuation and conservation: conflicting perception by local farmers in the Luangwa Valley, eastern Zambia", International Journal of Biodiversity and Conservation, vol. 5 (11): 741-750.

[21] Owen, G.T. 2014. "Qualitative methods in higher education policy analysis: Using interviews and document analysis", The Qualitative Report, 19(26):1-19.

[22] Pimbert, M. P. and Pretty, J. 1994. Participation, People and the Management of National Parks and Protected Areas. IIED, London, UK

[23] Potter, G. 2010. “Environmental education for the 21st century: Where do we go now?" The Journal of Environmental Education 41 (1): 22-33. http://dx.doi.org/10.1080/00958960903209975 Accessed 14/09/2019

[24] Reed. M. 2008. Stakeholder participation for Environmental Management: A Literature Review. 8 Leeds: University of Leeds.

[25] Rist, S., Chidambaranathan, M., Escobar, C., Wiesmann, U. and Zimmermann, A. 2007. Moving from sustainable management to sustainable governance of natural resources: the role of social learning processes in rural India, Bolivia and Mali Journal of Rural Studies 23 (1): 219 - 237

[26] Rowe, G., Frewer, L., 2000. Public participation methods: a framework for evaluation in science. Technology and Human Values 25: 3-29.

[27] SPIMUN Annotations 2014. Environmental and culture- The role of Environmental culture in in Environmental problem solving - St Petersburg International model, United Nations. http://www.spimun.com/?p=articles\&id=45. Accessed 14/09/2019.

[28] UNDP. 2012. Strengthening management effectiveness and generating multiple environmental benefits within and around the greater Kafue national park and west Lunga national park in Zambia, Project document.

[29] Watson, F.G., Becker, M.S., Milanzi, J. and Nyirenda, M. 2014. "Human encroachment into protected area networks in Zambia: Implications for large carnivore conservation", Regional Environmental Change, 15 (2): 415-429.

[30] ZAWA (Zambia Wildlife Authority). 1998. Zambia Wildlife Act. Chilanga, Lusaka, Zambia. http://theredddesk.org/sites/default/files/wildlife_act_12_1998_1.pdf, visited 14 September 2019

[31] ZAWA (Zambia Wildlife Authority). 2004. Quota setting and monitoring of hunting manual. Lusaka, Zambia Wildlife Authority

\section{AUTHORS' BIOGRAPHY}

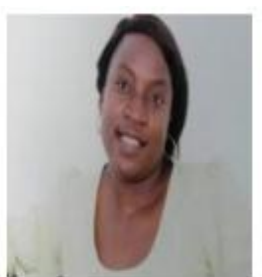

Inonge Milupi, D (PhD), is a lecturer and researcher of Environmental Education at the University of Zambia and a Post-Doctoral fellow at the University of Waterloo in Canada. Her research interest includes Environment and Society, Climate Change, Gender, Natural Resource Conservation and Indigenous Knowledge

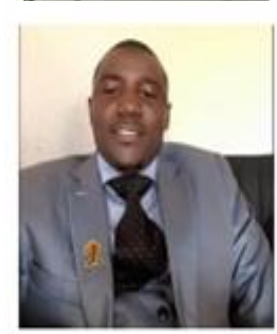

Kaiko Mubita (PhD), is a lecturer and researcher of Geography and Environmental Education at the University of Zambia. His research interests are in Occupational Health and Safety, Environmental Hazards and Disasters and Geography Education

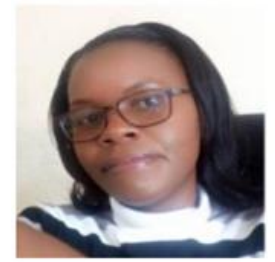

Pauline N. Monde is a lecturer and researcher at the University of Zambia in the Department of Language and Social Sciences Education. She is currently enrolled for PhD in Environmental Education at the same institution. Her areas of research interests include but not limited to Environmental Management, Environmental Governance and Ecological issues. 
Developing an Environmental Education programme to address factors behind weak Community Participation in Wildlife Resource Management in Mumbwa and Lupande Game Management areas in Zambia

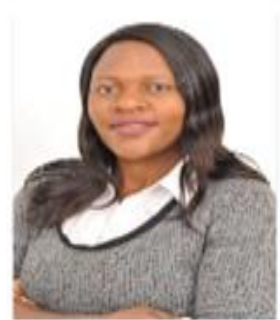

Steriah M. Simooya, is a lecturer and researcher at the University of Zambia in the Department of Language and Social Sciences Education. Her areas of research interest include but not limited to Environmental Management, Environmental Journalism and Environmental Education.

Citation: Inonge Milupi, D, et.al. " Developing an Environmental Education programme to address factors behind weak Community Participation in Wildlife Resource Management in Mumbwa and Lupande Game Management areas in Zambia" International Journal of Humanities Social Sciences and Education (IJHSSE), vol 7, no. 12, 2020, pp. 53-63. doi: https://doi.org/10.20431/2349-0381.0712007.

Copyright: (c) 2020 Authors. This is an open-access article distributed under the terms of the Creative Commons Attribution License, which permits unrestricted use, distribution, and reproduction in any medium, provided the original author and source are credited. 